\title{
Equal work for unequal pay: the gender reimbursement gap for healthcare providers in the United States
}

\author{
Tejas Desai, ${ }^{1,2}$ Sadeem Ali, $^{3}$ Xiangming Fang, ${ }^{4}$ Wanda Thompson, ${ }^{5}$ Pankaj Jawa, ${ }^{3}$ \\ Tushar Vachharajani ${ }^{1}$
}

'Division of Nephrology, WG (Bill) Hefner VA Medical Center, Salisbury, North Carolina, USA

${ }^{2}$ NOD Analytics, Charlotte, North Carolina, USA ${ }^{3}$ Division of Nephrology, East Carolina University—Brody School of Medicine, Greenville, North Carolina, USA ${ }^{4}$ Department of Biostatistics, East Carolina UniversityBrody School of Medicine, Greenville, North Carolina, USA

${ }^{5}$ Office of the Chief of Staff, WG (Bill) Hefner VA Medical Center, Salisbury, North

Carolina, USA

\section{Correspondence to} Dr Tejas Desai, Division of Nephrology, Department of Medicine, 1601 Brenner Avenue, Building 21, Salisbury, NC 28144, USA;

Tejas.p.desai@gmail.com

Received 14 March 2016 Revised 31 May 2016 Accepted 7 June 2016 Published Online First 15 August 2016

\section{SLinked}

- http://dx.doi.org/10.1136/ postgradmedj-2016-134313

- http://dx.doi.org/10.1136/ postgradmedj-2016-134346

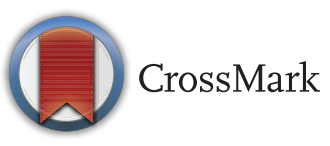

To cite: Desai T, Ali $S$ Fang $\mathrm{X}$, et al. Postgrad Med J 2016:92:571-575.

\section{ABSTRACT}

Introduction Gender disparities in income continue to exist, and many studies have quantified the gap between male and female workers. These studies paint an incomplete picture of gender income disparity because of their reliance on notoriously inaccurate or incomplete surveys. We quantified gender reimbursement disparity between female and male healthcare providers using objective, non-self-reported data and attempted to adjust the disparity against commonly held beliefs as to why it exists.

Methods We analysed over three million publicly available Medicare reimbursement claims for calendar year 2012 and compared the reimbursements received by male and female healthcare providers in 13 medical specialties. We adjusted these reimbursement totals against how hard providers worked, how productive each provider was, and their level of experience. We calculated a reimbursement differential between male and female providers by primary medical specialty. Results The overall adjusted reimbursement differential against female providers was -US\$18 677.23 (95\% Cl -US\$19 301.94 to -US\$18 052.53). All 13 specialties displayed a negative reimbursement differential against female providers. Only two specialties had reimbursement differentials that were not statistically significant.

Conclusions After adjustment for how hard a physician works, his/her years of experience and his/her productivity, female healthcare providers are still reimbursed less than male providers. Using objective, non-survey data will provide a more accurate understanding of this reimbursement inequity and perhaps lead the medical profession (as a whole) towards a solution that can reverse this decades-old injustice.

\section{INTRODUCTION}

For decades studies have shown inequities in pay between women and men. Some of the earliest analyses of pay inequity were conducted in the 1970s, and, since that time, reports indicate that women consistently earn less than their male contemporaries. ${ }^{1}{ }^{2}$ Indeed one would be hard pressed to identify a single calendar year in which female workers achieved earnings parity with their male counterparts.

Many studies have theorised that pay disparities result from women (1) undervaluing the services they provide, (2) working fewer hours and/or (3) being less productive. ${ }^{3-10}$ Unfortunately, these theories are based on analyses of data that are susceptible to bias and/or not adjusted for confounding variables. ${ }^{11}{ }^{12} \mathrm{~A}$ large proportion of these studies rely on self-reported income and many do not adjust for factors that could influence gender pay. ${ }^{13}{ }^{14}$ With such limitations, we believe that the medical community could improve upon its understanding of gender pay inequality. We quantified gender reimbursement disparity between female and male healthcare providers using objective, non-self-reported data and attempted to adjust the disparity against commonly held beliefs as to why it exists.

\section{METHODS}

We obtained healthcare provider reimbursement data for various medical specialties using the 2014 Medicare Fee-for-Service Provider Utilisation and Payment Data Physician and Other Supplier Public Use File (PUF) (http://www.cms.gov/apps/ama/ license.asp? file $=$ http://download.cms.gov/ResearchStatistics-Data-and-Systems/Statistics-Trends-andReports/Medicare-Provider-Charge-Data/Down loads/Medicare_Provider_Util_Payment_PUF_CY 2012_update.zip). This freely available dataset contains the practice locations, primary medical specialty, sex, reimbursements paid, services provided, and beneficiaries seen of, to and by healthcare providers participating in the Centers for Medicare and Medicaid Services (CMS) Part B fee-for-service programme in the USA for calendar year 2012. ${ }^{15}$ The CMS Office of Information Products and Data Analytics used data from the National Claims History Standard Analytic Files to create the Medicare PUF. The data in the PUF are not self-reported by individual healthcare providers. ${ }^{15}$

Unlike survey data used by previous investigators, the 2014 Medicare PUF did not include: hours worked, non-clinical earnings, bonus/incentive/performance monies, medical school type/location/ graduation date, or years in clinical practice. The PUF included the National Provider Identifier (NPI), which we used to estimate the years in clinical practice for each provider. The National Plan and Provider Enumeration System (NPPES) generates a unique NPI for each healthcare provider. ${ }^{16} 17$ Each provider receives an NPI from NPPES once and uses that NPI to submit reimbursement claims to CMS during the entirety of their active clinical practice. We cross-referenced the NPI listed in the 2014 Medicare PUF with the NPPES Data Dissemination File (http://download.cms.gov/nppes/ NPI_Files.html) and calculated the time between 
the year a provider's NPI was generated (enumeration year) and the year 2012. We used this value as a surrogate for years of clinical experience.

We calculated reimbursement differentials between reimbursements paid to female and male providers. Subsequently, we performed multivariate analyses of reimbursement differential against a number of confounding variables. Based on the work of Weeks et $a l^{3}{ }^{3}$ Baker $^{5}$ and Seabury et al, ${ }^{18}$ we included the following confounders in our model: primary medical specialty, years of clinical experience, hours worked and productivity. The first confounder was included in the 2014 PUF. Using the NPI enumeration year, we calculated a surrogate value for the number of years of clinical experience. We used the number of Medicare beneficiaries seen as a surrogate for the total number of hours worked delivering care to patients. Based on data presented in The Physicians Foundation Annual Report and The Washington Post, we assumed that providers who delivered care to more beneficiaries were likely to have worked more hours than those who delivered care to fewer beneficiaries. ${ }^{19} 20$ Similarly, we assumed that the number of services provided would be an appropriate surrogate for productivity: the greater the number of services provided, the greater the productivity. ${ }^{19} 20$

We restricted our analyses to providers who self-identified as practicing internal medicine, family practice, or a medical specialty, such as cardiology, endocrinology, nephrology, rheumatology, haematology, medical oncology, haematology and oncology, pulmonary, critical care, infectious disease or gastroenterology.

We used Microsoft Excel and JMP to perform multiple linear regression analyses and calculated an adjusted reimbursement differential between women and men. Our statistical threshold for significance was $p<0.05$. Wherever possible, we followed the STROBE and SAMPL guidelines for conducting observational research and reporting results, respectively. ${ }^{21} 22$ The institutional review boards of the Department of Veterans Affairs (Salisbury, North Carolina, USA) and East Carolina UniversityBrody School of Medicine (Greenville, North Carolina, USA) approved this study.

\section{RESULTS}

The Medicare PUF for calendar year 2012 contained 9153273 records for 882125 providers. We included the records of providers in 13 medical specialties, resulting in 3549862 records for 246995 providers. We were either missing or unable to download and/or analyse records for 1344 providers $(0.5 \%)$. Of the remaining providers in our dataset (245 651), nearly 70\% were generalists in either internal medicine $(91336 ; 37 \%)$ or family practice $(77452 ; 32 \%)$. The greatest number of specialists was in cardiology $(22150 ; 9 \%)$ and the fewest in haematology $(682 ; 0.3 \%)$.

The dataset with which we worked had a 70:30 ratio of male to female providers. Cardiology had the lowest percentage of female providers $(10.7 \%)$. No specialty had an equal percentage of male/female providers; endocrinology came close to parity with a male/female ratio of 57:43. Tables 1 and 2 summarise our baseline data.

In the unadjusted analysis, female providers were reimbursed US\$34 125.68 (95\% CI -US\$34 991.61 to -US\$33 259.76) less. Six specialties had a female reimbursement differential greater than the overall differential (cardiology, haematology/ oncology, haematology, nephrology, medical oncology and rheumatology); all differentials were statistically significant. The narrowest reimbursement differentials were in family practice (-US\$15 029.77 (95\% CI -US\$15 627.83 to -US\$14 431.70)) and infectious disease (-US\$19 $176.82 \quad(95 \%$ CI $\quad$-US $\$ 23177.82$ to -US\$15 175.83)), but female providers had a statistically significant gap in reimbursement compared with male providers in every specialty. Table 3 summarises the unadjusted analysis.

In the adjusted analysis, we used surrogate observations to account for three confounders purported to affect the disparity in gender reimbursement: years of experience (surrogate: years since NPI enumerated), productivity (surrogate: number of services provided) and hours worked (surrogate: number of beneficiaries seen). The overall adjusted reimbursement differential was -US\$18 677.23 (95\% CI -US\$19 301.94 to -US $\$ 18$ 052.53). Nephrology displayed the largest statistically significant gender differential of -US\$16 688.96 (95\% CI -US $\$ 21437.04$ to $-\mathrm{US} \$ 11940.88$ ). Of the 13 specialties, only haematology and medical oncology had differentials that were not statistically significant. Table 3 and figure 1 summarise the adjusted analyses.

\section{DISCUSSION}

After adjustment for hours worked, productivity and level of experience, female healthcare providers received lower reimbursements than their male counterparts. Investigators have often cited at least one of these explanations for the disparity in physician pay. ${ }^{3}$ 5-9 23 Despite these adjustments, female providers received statistically lower reimbursements in 11 of 13 medical specialities.

Weeks and Wallace have extensively analysed the income disparities for physicians. ${ }^{3-9}$ Their work has revealed widespread inequality in an overwhelming number of specialties and has led them to conclude that three variables are likely to affect this inequality: physician effort, physician experience and practice characteristics. In the present investigation, we adjusted for physician effort and experience using objective, non-self-reported surrogate observations. We were unable to adjust for practice characteristics because the Medicare PUF did not contain such information.

Baker $^{5}$ and Sasser ${ }^{23}$ expounded on the theories of Weeks and Wallace by suggesting that type of specialty affects physician income. Female physicians are more likely to work in less lucrative specialties, so their incomes will be lower than their male counterparts who more commonly work in highly lucrative fields. Baker's work also shed light on the factors that did not affect income, namely biological age, ethnic group and type/ geography of medical school. ${ }^{5}$ Therefore, we adjusted our analysis for 13 medical specialties. We found that in 11 of these specialties, female providers received statistically less reimbursement than male providers irrespective of the amount worked, level of productivity or years of experience.

In 2009, Cron and Gilly reintroduced 'inherent value' to the discussion of gender pay inequality. ${ }^{24}$ Female workers receive less money because they price their services lower than male counterparts. This idea may hold true in traditional industries. In healthcare, insurance companies set the price for most services, with a heavy reliance on the pricing trends established by Medicare. Differences in prices are more likely to be due to geographic considerations or concomitant services provided than the negotiating prowess of individual providers. ${ }^{25}$ As a result, individual providers are less likely to undervalue themselves because they are unlikely to broadly affect prices for healthcare services.

Seabury et $\mathrm{al}^{18}$ have provided one of the most comprehensive analyses of gender income inequality in healthcare. After analysing self-reported data in the March Current Population Survey 
Table 1 Specialty-specific baseline data

\begin{tabular}{|c|c|c|c|c|c|c|c|c|}
\hline Specialty & $\begin{array}{l}\text { Records } \\
\text { (n) }\end{array}$ & $\begin{array}{l}\text { Total Medicare } \\
\text { payment (US\$) }\end{array}$ & $\begin{array}{l}\text { Portion of total } \\
\text { Medicare payment } \\
(\%)\end{array}$ & $\begin{array}{l}\text { Total beneficiaries } \\
\text { seen }(n)\end{array}$ & $\begin{array}{l}\text { Portion of } \\
\text { beneficiaries } \\
\text { seen }(\%)\end{array}$ & $\begin{array}{l}\text { Providers } \\
\text { (n) }\end{array}$ & $\begin{array}{l}\text { Male } \\
(\%)\end{array}$ & $\begin{array}{l}\text { Female } \\
(\%)\end{array}$ \\
\hline All & 3549862 & 28263199739.28 & 100.0 & 274669868 & 100.0 & 245651 & 69.8 & 30.2 \\
\hline Cardiology & 535359 & 4965536980.20 & 17.6 & 55308660 & 20.1 & 22150 & 89.4 & 10.6 \\
\hline Endocrinology & 52126 & 387291151.12 & 1.4 & 5244848 & 1.9 & 4786 & 56.9 & 43.1 \\
\hline Critical care & 19196 & 208382904.46 & 0.7 & 1235739 & 0.4 & 2163 & 79.4 & 20.6 \\
\hline Family practice & 970873 & 4372944047.90 & 15.5 & 63021587 & 22.9 & 77452 & 64.9 & 35.1 \\
\hline Gastroenterology & 172708 & 1344335879.10 & 4.8 & 10876759 & 4.0 & 11991 & 86.6 & 13.4 \\
\hline $\begin{array}{l}\text { Haematology/ } \\
\text { oncology }\end{array}$ & 182034 & 2703879368.90 & 9.6 & 11607555 & 4.2 & 7348 & 72.0 & 28.0 \\
\hline Infectious disease & 36701 & 523363211.33 & 1.9 & 3132146 & 1.1 & 4762 & 64.1 & 35.9 \\
\hline Internal medicine & 1197465 & 8736311072.30 & 30.9 & 95001597 & 34.6 & 91336 & 66.0 & 34.0 \\
\hline Nephrology & 107806 & 1685606837.30 & 6.0 & 8094556 & 2.9 & 7483 & 77.2 & 22.8 \\
\hline Haematology & 9631 & 127615053.23 & 0.5 & 542408 & 0.2 & 682 & 70.3 & 29.7 \\
\hline Medical oncology & 55014 & 806637769.54 & 2.9 & 3445250 & 1.3 & 2598 & 71.9 & 28.1 \\
\hline Rheumatology & 69402 & 1044462027.40 & 3.7 & 5670752 & 2.1 & 4065 & 62.3 & 37.7 \\
\hline Pulmonary & 141547 & 1356833436.50 & 4.8 & 11488011 & 4.2 & 8835 & 83.8 & 16.2 \\
\hline
\end{tabular}

and adjusting for race, age, sex, hours worked and practice location, they revealed a US\$33 840.00-US\$56 019.00 income range differential between female and male providers. This differential straddles the US\$34 125.68 unadjusted differential (95\% CI -US\$34 991.61 to -US\$33 259.76) that we report, but is double the US\$18 677.23 adjusted differential in our analysis. The discrepancies between these investigations may be due to different sample sizes (38 115 vs 245651 ), the manner in which data were collected (self-reported in the Seabury study), and/or the inability to adjust for specialty or procedural volume using the March Current Population Survey dataset. ${ }^{14} 18$

We recognise that the work of these investigators has provided the foundation on which contemporary analyses, such as our own, have been performed. Unfortunately, these antecedent studies relied on survey data from various sources, including the American Medical Association, Survey of Young Physicians, US Census Bureau, Bureau of Labor Statistics, and/or March Current Population Survey. ${ }^{3}$ 5-9 182324 Despite our belief in the methodologies of these surveys, there are unavoidable biases that percolate through them which can negatively impact their analysis. $^{13} 26$ Our investigation used reimbursement claims information-data that are not self-reported. In so far as these data are not self-reported, analysis of the Medicare PUF should not be plagued by low survey response rates or measurement/ sampling biases. ${ }^{10-1227}$

\section{STRENGTHS AND LIMITATIONS}

The size and type of data analysed help strengthen our analyses and conclusions. The Medicare PUF contains observational data for all providers that billed Medicare Part B for services in calendar year 2012. We analysed data from over 245000 providers. Our study is one of the largest to address gender pay inequity in recent years, including the recently released Doximity survey of 35000 providers. ${ }^{28}$ Equally important is the fact that the data for these providers are objective. Consequently, the PUF is less susceptible to poor response rates or self-reporting biases that can exist when survey data are used. $^{3} 5-9182324$

Table 2 Gender-specific baseline data

\begin{tabular}{|c|c|c|c|c|c|c|c|c|}
\hline \multirow[b]{2}{*}{ Specialty } & \multicolumn{2}{|c|}{ Providers (n) } & \multicolumn{2}{|c|}{ Total beneficiaries seen $(n)$} & \multicolumn{2}{|c|}{ Total services provided (n) } & \multicolumn{2}{|c|}{$\begin{array}{l}\text { Total years } \\
\text { experience }(n)\end{array}$} \\
\hline & Male & Female & Male & Female & Male & Female & Male & Female \\
\hline All & 171541 & 74110 & 223225015 & 50770959 & 677000816 & 148801021 & 1183715 & 489934 \\
\hline Cardiology & 19802 & 2348 & 51313193 & 3993546 & 83771357 & 5856627 & 140606 & 16046 \\
\hline Endocrinology & 2725 & 2061 & 3796148 & 1448700 & 7234704 & 2601555 & 18947 & 13763 \\
\hline Critical care & 1718 & 445 & 1076601 & 159138 & 2214813 & 282652 & 11700 & 2942 \\
\hline Family practice & 50254 & 27198 & 47637820 & 14720729 & 92736700 & 28404125 & 348093 & 181219 \\
\hline Gastroenterology & 10386 & 1605 & 10008152 & 868388 & 13656191 & 1167344 & 73568 & 10859 \\
\hline Haematology/oncology & 5292 & 2056 & 9341629 & 2265926 & 160103650 & 33169364 & 37152 & 13958 \\
\hline Infectious disease & 3051 & 1711 & 2256342 & 875804 & 28310374 & 10642175 & 21094 & 11376 \\
\hline Internal medicine & 60260 & 31076 & 73265663 & 21727372 & 155764716 & 41058123 & 405634 & 201965 \\
\hline Nephrology & 5775 & 1708 & 6722827 & 1371676 & 31868322 & 5609422 & 40584 & 11508 \\
\hline Haematology & 479 & 203 & 409451 & 132957 & 6710182 & 1340539 & 3319 & 1376 \\
\hline Medical oncology & 1867 & 731 & 2752351 & 692899 & 46202567 & 8716131 & 13116 & 4973 \\
\hline Rheumatology & 2534 & 1531 & 4361989 & 1308763 & 29587851 & 7918219 & 17882 & 10268 \\
\hline Pulmonary & 7407 & 1428 & 10282849 & 1205061 & 18839389 & 2034745 & 52020 & 9681 \\
\hline
\end{tabular}


Table 3 Adjusted and unadjusted gender reimbursement differentials for 13 medical specialties

\begin{tabular}{|c|c|c|c|c|c|c|}
\hline Specialty & $\begin{array}{l}\text { Unadjusted differential } \\
\text { (US\$) }\end{array}$ & $\begin{array}{l}\text { 95\% Cl lower } \\
\text { (US\$) }\end{array}$ & $\begin{array}{l}\text { 95\% Cl upper } \\
\text { (US\$) }\end{array}$ & $\begin{array}{l}\text { Adjusted differential } \\
\text { (US\$) }\end{array}$ & $\begin{array}{l}\text { 95\% Cl lower } \\
\text { (US\$) }\end{array}$ & $\begin{array}{l}95 \% \mathrm{Cl} \text { upper } \\
\text { (US\$) }\end{array}$ \\
\hline All & -34125.68 & -34991.61 & -33259.76 & -18677.23 & -19301.94 & -18052.53 \\
\hline Cardiology & -49532.75 & -54955.76 & -44109.75 & -8700.69 & -12216.92 & -5184.46 \\
\hline Endocrinology & -21583.72 & -24379.99 & -18787.44 & -5680.17 & -7081.80 & -4278.54 \\
\hline Critical care & -21161.13 & -28712.74 & -13609.52 & -4360.05 & -8184.85 & -535.24 \\
\hline Family practice & -15029.77 & -15627.83 & -14431.70 & -8152.83 & -8609.44 & -7696.21 \\
\hline Gastroenterology & -26556.29 & -28968.12 & -24144.45 & -4636.67 & -5761.80 & -3511.55 \\
\hline Haematology/oncology & -94350.55 & -109996.00 & -78705.13 & -7377.09 & -13381.58 & -1372.59 \\
\hline Infectious disease & -19176.82 & -23177.82 & -15175.83 & -6527.46 & -9275.38 & -3779.55 \\
\hline Internal medicine & -24158.97 & -25003.32 & -23314.62 & -10850.34 & -11443.72 & -10256.97 \\
\hline Nephrology & -41776.96 & -47751.56 & -35802.36 & -16688.96 & -21437.04 & -11940.88 \\
\hline Haematology & -52257.03 & -86317.14 & -18196.91 & $-10115.08^{*}$ & -21616.48 & 1386.32 \\
\hline Medical oncology & -81433.39 & -106482.80 & -56383.97 & $-3970.50^{*}$ & -13903.06 & 5962.05 \\
\hline Rheumatology & -85356.80 & -98925.86 & -71787.74 & -15405.54 & -21832.93 & -8978.15 \\
\hline Pulmonary & -32543.52 & -36514.82 & -28572.21 & -11017.79 & -13442.74 & -8592.84 \\
\hline
\end{tabular}

*Values did not meet the threshold for statistical significance.

Another strength is our ability to adjust for variables that have been proposed to be the reasons for gender pay inequality. ${ }^{29} 30$ After adjusting for physician work hours, productivity and years of experience, we found a statistically significant gender reimbursement differential in $85 \%$ of specialties analysed.

As with all investigations, ours has limitations worthy of mention. First, we used surrogate markers to estimate physician work hours, productivity and years of experience. Prior investigations have directly measured these variables through the use of surveys. ${ }^{3}$ 5-9 $18 \quad 23 \quad 24 \quad 28$ We knowingly used surrogate variables in our analyses to avoid the uncertainties of working with survey data. ${ }^{11}$ Second, we analysed reimbursements from Medicare Part B only. While Medicare is the largest insurer of patients in the USA, we ignored reimbursements from other agencies/companies, including other federal programmes (eg, Federal Employees Health Benefits, Tricare) and the Medicare Advantage plan. ${ }^{15} 2931$ Could there be more female providers receiving higher reimbursements from other agencies than male providers? The data needed to answer this and other questions were not available to us. Had it been available, our analyses would have provided an even more complete picture of reimbursement differentials. Third, our analysis does not address quality of care. Because the Medicare PUF does not contain such information, we do not know if quality of care affects provider reimbursement. ${ }^{15}$ Lastly, and perhaps most regrettably, we still do not have an answer as to why female providers are reimbursed less than their male counterparts.

\section{CONCLUSIONS}

Reimbursement differentials between male and female providers continue to exist in a large proportion of medical specialties. Our findings suggest that the commonly held theories of why monetary disparities exist need to be revisited. ${ }^{32}$ After adjustment for work hours, years of experience and productivity, female healthcare providers are still reimbursed less than male providers. Despite using Medicare Part B data to ascertain specialty-specific reimbursement differentials, we have no reason to believe that such differentials exist only in this dataset. If there is a disparity in gender reimbursement that is independent of the health insurance company that is billed, then future research should be performed to uncover this pattern. Only then can the medical community have the most accurate understanding of the reimbursement inequity and perhaps be guided towards a solution that can reverse this decades-old injustice. ${ }^{34-36}$

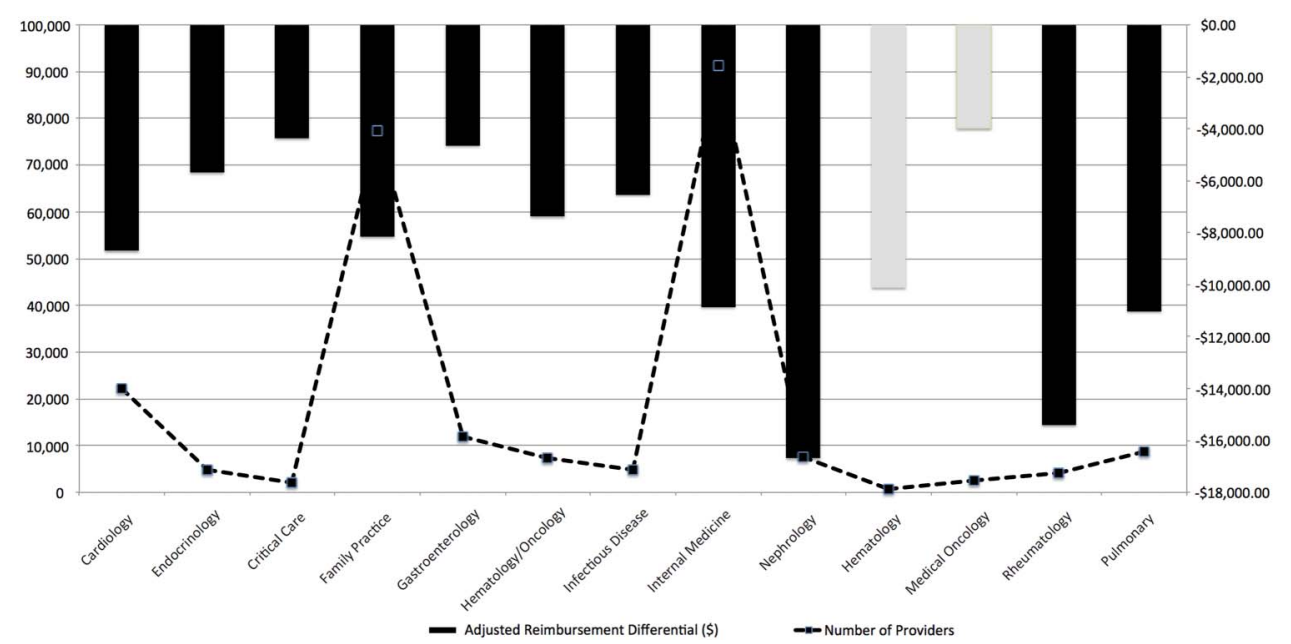

Figure 1 Adjusted specialty-specific reimbursement differentials (bars) against number of providers (dotted line). Black bars: $p<0.05$. 


\section{Main messages}

- Female healthcare providers are reimbursed less than their male contemporaries.

- The Medicare Public Use File is one of the largest publicly accessible databases to contain reimbursement data.

- After adjustment for productivity, amount of work and years of experience, female providers are reimbursed less than their male counterparts.

\section{Current research questions}

- Is the reimbursement disparity limited to Medicare, or is it seen with other insurance companies?

- Can we quantify hours worked and productivity in a more direct manner than using surrogates or survey data?

- How can the medical profession resolve the gender disparity in reimbursement?

\section{Twitter Follow Tejas Desai at @nephondemand (goo.gl/mfziXG)}

Contributors TD: designed the experiment, performed data analyses and drafted manuscript. SA: designed the experiment. XF: performed data analyses. WT, PJ, TV: designed the experiment.

Competing interests None declared.

Provenance and peer review Not commissioned; externally peer reviewed.

\section{REFERENCES}

1 Mazzolini C. Practices grapple with new pressures. Medical Economics. 11/10/2014. http://medicaleconomics.modernmedicine.com/medical-economics/news/ physician-practices-grapple-new-financial-pressures?page=full (retrieved 1 Dec 2014).

2 The Simple Truth about the Gender Pay Gap. American Association of University Women. 2015. http://www.aauw.org/files/2015/09/The-Simple-Truth-Fall-2015.pdf (retrieved 30 Dec 2015)

3 Weeks WB, Wallace AE, Mackenzie TA. Gender differences in anesthesiologists annual incomes. Anesthesiology 2007;106:806-11.

4 Kaldenberg DO, Becker BW. Work and commitment among young professionals: a study of male and female dentists. Hum Relations 1995;48:1355-77.

5 Baker LC. Differences in earnings between male and female physicians. N Engl J Med 1996;334:960-4.

6 Weeks WB, Wallace AE. Differences in the annual incomes of emergency physicians related to gender. Acad Emerg Med 2007;14:434-40.

7 Weeks WB, Wallace AE. Gender differences in ophthalmologists' annual incomes. Ophthalmology 2007;114:1696-701.

8 Weeks WB, Wallace AE. The influence of race and gender on family physician's annual incomes. J Am Board Fam Med 2006;19:548-56.

9 Weeks WB, Wallace AE. Race and gender differences in general internists' annual incomes. J Gen Intern Med 2006;21:1167-71.

10 Coplan B, Essary AC, Virden TB, et al. Salary discrepancies between practicing male and female physician assistants. Women's Health Issues 2012;22:e83-9.

11 Woodruff B, Bornemisza O, Checchi F, et al. The use of epidemiological tools in conflict-affected populations: open-access educational resources for policy makers. 2009. 2015. http://conflict.Ishtm.ac.uk/page_39.htm

12 Perlich P. Survey Research: Errors and Limits. 2012. http://home.business.utah.edu/ bebrpsp/URPL5010/Lectures/7_ErrorSources.pdf (retrieved 30 Dec 2015).

13 Moore JC, Stinson LL, Welniak EJ. Income measurement error in surveys: a review. United States Census Bureau. https://www.census.gov/srd/papers/pdf/sm97-05.pdf (retrieved 13 Jan 2016).
14 Geisen E, Strohm C, Stringer C, et al. Examining the relationship between the accuracy of self-reported data and the availability of respondent financial records. RTI International, 2012. https://www.rti.org/pubs/aapor12_geisen_paper.pdf (retrieved 13 Jan 2016).

15 Medicare Fee-for Service Provider Utilization \& Payment Data Physician and Other Supplier Public Use File: A Methodological Overview.. Center for Medicare and Medicaid Services Office of Information Products and Data Analytics. 2014. https:/l www.cms.gov/Research-Statistics-Data-and-Systems/Statistics-Trends-and-Reports/ Medicare-Provider-Charge-Data/Downloads/Medicare-Physician-and-Other-SupplierPUF-Methodology.pdf (retrieved 1 May 2014).

16 National Plan and Provider Enumeration System Data Dissemination Public FileCode Values. 2013. https://www.cms.gov/Regulations-and-Guidance/HIPAAAdministrative-Simplification/NationalProvldentStand/Downloads/Data_ Dissemination_File-Code_Values.pdf (retrieved 1 May 2014).

17 National Plan and Provider Enumeration System Data Dissemination Public File- Readme. 2013. https://www.cms.gov/Regulations-and-Guidance/HIPAA-AdministrativeSimplification/NationalProvldentStand/Downloads/Data_Dissemination_File-Readme.pdf (retrieved 1 May 2014).

18 Seabury SA, Chandra A, Jena AB. Trends in the earnings of male and female health care professionals in the United States, 1987 to 2010. JAMA Intern Med 2013;173:1748-50.

19 A Survey of America's Physicians: Practice Patterns and Perspectives. The Physicians Foundation. 2012. http://www. physiciansfoundation.org/uploads/default/Physicians Foundation_2012_Biennial_Survey.pdf (retrieved 30 Dec 2015).

20 Bernstein L. How many patients should your doctor see each day? The Washington Post 22 May 2014. http://wpo.st/ViX31 (retrieved 13 Jan 2016).

21 von Elm E, Altman DG, Egger M, et al. The Strengthening the Reporting of Observational Studies in Epidemiology (STROBE) statement: guidelines for reporting observational studies. PLoS Med 2007;4:e296.

22 Lang TA, Altman DG. Basic Statistical Reporting for Articles Published in the Biomedical Journals: The "Statistical Analyses and Methods in the Published Literature" or The "SAMPL Guidelines". September 2013. http://www. equator-network.org/wp-content/uploads/2013/03/SAMPL-Guidelines-3-13-13.pdf (retrieved 29 Oct 2013).

23 Sasser AC. The role of gender and family in the labor market. Ann Arbor, MI: Bell and Howell Information and Learning Company, 2001.

24 Cron WL, Gilly MC, Graham JL, et al. Gender differences in the pricing of professional services: implications for income and customer relationships. Organ Behav Hum Decis Processes 2009:109:93-105.

25 MaCurdy T, Shafrin J, DelEiure T, et al. Geographic Adjustment of Medicare Payments to Physicians: Evaluation of IOM Recommendations. 2012. https://www. cms.gov/medicare/medicare-fee-for-service-payment/physicianfeesched/downloads/ geographic_adjustment_of_medicare_physician_payments_july2012.pdf (retrieved 30 Dec 2015).

26 Limitations of the Data. United States Census Bureau. https://www.census.gov/prod/ 1/gen/95statab/app3.pdf (retrieved 13 Jan 2016).

27 Bacon D. Results of the 2009 AORN Salary Survey. AORN J 2009;90:829-44.

28 Davis J. Physician Careers: Understanding the Market. Doximity. 2016. http://blog. doximity.com/post/138152892296/physician-careers-understanding-the-market (retrieved 27 Jan 2016).

29 Ambati B. Gender income disparities can be explained by alternative factors. JAMA Intern Med 2014;174:822

30 Cooke M. Persistent earnings inequities for female physicians: still the same old story. JAMA Intern Med 2013;173:1750.

31 Beard K. Large Gender Pay Gap for Medicare Physicians. Law and Health 30 April 2014. http://health.wolterskluwerlb.com/2014/04/large-gender-pay-gap-formedicare-physicians/ (retrieved 30 Dec 2015).

32 Fitch A. Why Women Doctors Make Half of What Men Do: Medicare's Doctor Gender Pay Gap. Nerdwallet, 22 Apr 2014. https://www.nerdwallet.com/blog/ health/doctor-salary-gender-pay-gap/

33 NerdWallet Medicare Reimbursement Data. 22 April 2014. http://www.nerdwallet. com/blog/health/personal-health-finance/doctor-salary-gender-pay-gap/ (retrieved 30 Dec 2015).

34 Hurtubise S. Study: Medicare pays male doctors more. The Daily Caller News Foundation 22 April 2014. http://dailycaller.com/2014/04/22/study-medicare-paysmale-doctors-more/ (retrieved 30 Dec 2015).

35 Miller C. How to bridge that stubborn pay gap. The New York Times 15 January 2016. http://nyti.ms/1JOsZAO (retrieved 15 Jan 2016).

36 Rosenfeld J, Denice P. The power of transparency: evidence from a British Workplace Survey. Am Sociol Rev 2015;80:1045.

37 Presidential Documents, Memorandum of April 8, 2014. Advancing pay equality through compensation data collection. Federal Register 2014;79:20751. 